\title{
Impact of Individual Habits on the Implementation of a Sustainable Transport System
}

\author{
Abbas Mohammed Kadum Algburi ${ }^{1}$, Hazim Jwad Rasoul ${ }^{2}$ \\ ${ }^{1}$ Dept. of Civil Engineering and Mechanics, Hauzhang University of Science and Technology, Hubei, Wuhan, China \\ ${ }^{2}$ Dept. of Civil Engineering and Mechanics, Hauzhang University of Science and Technology, Hubei, Wuhan, China
}

\begin{abstract}
Current usage of transport is unsustainable, leading to the planet facing major global climate change challenges in future decades fueled by population will increase, accrued average incomes and material consumption. This successively makes reducing national and world emissions a troublesome task: transport accounts for twenty fifth of the UK's CO2 emissions (CO2) with UK and worldwide greenhouse gas emission concentrations at their highest levels since records began. Property and sustainable transport are terms usually utilized in daily voice communication, academe and political agendas, hence however do planners and policy manufacturers with success implement a sustainable transport system? Recent tutorial analysis, designing and transport policy have all focused on the motored traveler instead of the non-motorized, and afterwards an absence of information has developed in understanding however habits have an effect on travel movement. It's the aim of this project to spot if habitual factors area unit acting as a stimulant or a barrier for the implementation of sustainable transport systems among the urban cloth.
\end{abstract}

Keywords: sustainable transport, individual habits, transport system, challenges

\section{Introduction}

Senses of sustainable transport within social, environmental sustainability refers to the broad theme of transportation and climate impacts and therefore ability to supply energy to global scope, within the offer indefinitely. Stability evaluation of elements for actual road, water or air transport vehicles used to hug; Energy supply; And so accustomed to infrastructure (roads, railways, Airways, waterways, canals and terminals) transport to adjust. Another element to the analysis of liquid or gas pipelines for the transport of the material. Transportation operations and so as transit-oriented development supply analysis are concerned. Transportation sustainability essentially being measured by similar effects and energy transit system environment and climate impacts.

While fossil-based energy migrating from transport renewable energy and alternate use of renewable resources for alternate options like long goal to embrace short-term activity usually fuel power and vehicle emissions control promotes progressive improvement. Measure the entire life cycle of transport system stability and is subject to customization. Sustainable transport, environmental, social and economic stability to make a positive contribution to the communities they serve. To produce social and economic connections exist, the transport system and offer others the opportunity to quickly enlarged take quality. Weighed against the environmental and social benefits of increased quality to be found due to economic prices and transportation systems.

Transport systems have important impacts on the atmosphere, accounting for between a pair of hundredth and twenty fifth of world energy consumption and oxide emissions. The majority of the emissions, almost 97\%, came from direct burning of fossil fuels. gas emissions from transport unit of measurement increasing at a faster rate than the opposite energy exploitation sector. Road transport is to boot a heavy contributor to native pollution and pollution.

The social costs of transport embrace road crashes, pollution, physical inactivity, time segregated from the family whereas commutation and vulnerability to fuel value can increase. Many of these negative impacts fall disproportionately on those social groups administrative body are least ostensibly to possess and drive cars. Holdup imposes economic costs by wasting people's time and by retardation the delivery of merchandise and services.

Traditional transport planning aims to reinforce quality, significantly for vehicles, and can fail to adequately have confidence wider impacts. however, the vital purpose of transport is access - to work, education, product and services, friends and family - and their unit verified techniques to reinforce access whereas at a similar time reducing environmental and social impacts, and managing holdup. Communities that unit successfully rising the property of their transport networks do thus as an area of a wider software engineer of creating plenty of spirited, livable, property cities.

The term property transport came into use as a logical innings from property development, and is utilized to clarify modes of transport, and systems of transport planning, that unit in step with wider problems with property. There unit many definitions of the property transport, and of the connected terms property transportation and property quality. One such definition, from the eu Union Council of Ministers of Transport, defines a property transit along that:

- Allows the elemental access and development desires of individuals, corporations and society to be met safely and through a fashion in step with human and system health, and promotes equity among and between consecutive generations. 


\section{International Journal of Science and Research (IJSR) \\ ISSN (Online): 2319-7064}

Index Copernicus Value (2013): 6.14 | Impact Factor (2015): 6.391

- Is affordable, operates fairly and efficiently, offers a range of transport mode, and supports a competitive economy, furthermore as balanced regional development.

- Uses non-renewable resources at or below the rates of development of renewable substitutes, whereas minimizing the impact on the use of land and thus the generation of noise and Limits emissions and waste among the planet's ability to take in them, uses renewable resources at or below their rates of generation.

A cradle-to-cradle vogue could be a ton of necessary than a spotlight on one issue like energy efficiency. Sustainability extends on the so much facet merely the operational efficiency and emissions. A Life-cycle assessment involves production, use and post-use problems.

\section{Research Background}

Most of the tools and concepts of process sustainable transport were developed before the phrase was coined. Walking, the first mode of transport is to boot the foremost property. Transport dates back a minimum of as most as a result of the invention of the overall public bus by mathematician in 1662. Initial the first someone tram began operation in 1807 and conjointly the primary someone rail service in 1825 . Pedal bicycles begin the decade. These were the only personal transport picks accessible to the bulk in Western countries before warfare II, and keep the only decisions for several people among the developing world. Freight was shifted by human power, animal power or rail.

The post-war years brought accrued wealth and a requirement for abundant larger quality for individuals and product. The quantity of road vehicles in United Kingdom increased multiple between 1950 and 1979, with similar trends in different Western nations. Most affluent countries and cities endowed heavily in larger and betterdesigned roads and motorways that were thought-about essential to underpin growth and prosperity. Transport developing with became a branch of technology and science and sought-after to vogue enough road capability to supply for the projected level of traffic growth at acceptable levels of tie up - a technique called "predict and provide". Public investment in transit, walking and athletics declined dramatically at intervals the North American nation, nice uk and Australia, this did not occur to identical extent in North American country or dry land Europe.

Concerns concerning the property of this approach became widespread throughout the 1973 oil crisis and conjointly the 1979 energy crisis. The high worth and restricted availableness of fuel semiconductor diode to an improvement of interest in alternatives to single occupancy vehicle travel.

Transport innovations analysis from this era embrace highoccupancy vehicle lanes, broad carpool systems and transportation demand management. Singapore enforced congestion valuation inside the late Seventies, and town began implementing its Bus transit system inside the first Eighties.

Relatively low and stable oil prices throughout the Eighties and Nineties light-emitting diode to special can increase in vehicle travel from 1980-2000, every directly as a results of people hand-picked to travel automobile further typically and for larger distances, and indirectly as a results of cities developed tracts of community housing, distant from retailers and from workplaces, presently discovered as geographical region. Trends in freight provision, also as a movement from rail and coastal shipping to road freight and a requirement for merely in time deliveries, meant that freight traffic grew faster than general vehicle traffic.

At identical time, the tutorial foundations of the "predict and provide" approach to maneuver were being questioned, notably by Peter Newman throughout a group of comparative studies of cities and their transport systems analysis from the mid-1980s.

The British Government's report on Transport marked a modification in direction for transport coming up with inside the United Kingdom. inside the introduction to the white paper, Prime Minister politician specific that we tend to tend to acknowledge that we tend to tend to cannot simply build our resolution of the problems we tend to tend to face. it might be environmentally trigger-happy and would not work.

A companion document to the report referred to as "Smarter Choices" researched the potential to proportion the insufficient and scattered property transport initiatives then occurring across UK, and every one over that the good application of these techniques might deflate peak quantity automobile travel in urban areas by over 2 hundredth.

A similar study by the US Federal Road Administration, was jointly discharged in 2004 and jointly everywhere that a further proactive approach to transportation demand was an awfully necessary a part of overall national transport strategy.

\section{Aims and Objectives of this Study}

- To outline the property transport debates from an area, national and international perspective.

- To perceive habitual behavior and concrete character through a case study approach. to gauge the impact that age and concrete characteristics wear individual's behavior associated to a property transport system. to tell new property transport policies aiding the reduction of greenhouse gas from automobile transit.

\section{Recent Trends}

Car travel increased steady throughout for the 20th century, but trends since 2000 is lots of difficult. Oil value rises from 2003 are connected to a decline in per capita fuel use for private vehicle travel at intervals the USA, nice United Kingdom and Australia. In 2008, world oil 


\section{International Journal of Science and Research (IJSR) \\ ISSN (Online): 2319-7064 \\ Index Copernicus Value (2013): 6.14 | Impact Factor (2015): 6.391}

consumption fell by each $0.8 \%$ overall, with important declines in consumption in North America, Western Europe, and parts of Asia. various factors poignant a decline in driving, a minimum of in America, embrace the retirement of Baby Boomers World Health Organization presently drive less, preference for various travel modes (such as transit) by younger age cohorts, the great Recession, and so the rising use of technology (internet, mobile devices) that have created travel less necessary and doubtless less partaking.

\section{Analysis and Impact of the Sustainable Transport}

Transport systems are major emitters of greenhouse gases, responsible for twenty third of world energy-related GHG emissions in 2004, with relating to three quarters returning from road vehicles. Presently ninety fifth of transport energy comes from fossil oil. Energy is consumed at intervals the manufacture in addition is use of vehicles, and is embodied in transport infrastructure at the side of roads, bridges and railways.

The atmosphere impacts of transport are going to be reduced by rising the walking and sport atmosphere in cities, and by enhancing the role of transport, notably electrical rail. Inexperienced vehicles are speculated to own less environmental impact than equivalent traditional vehicles, once the environmental impact of a vehicle is assessed over the whole of its life cycle this won't be the case. Electrical vehicle technology has the potential to chop back transport $\mathrm{CO} 2$ emissions, depending on the embodied energy of the vehicle and conjointly the availability of the electricity. the online electrical Vehicle (OLEV), developed by the Korean Peninsula Advanced Institute of Science and Technology (KAIST), is AN electrical vehicle which is able to be charged whereas stationary or driving, thus removing the necessity to forestall at a charging station. the city of Gumi in Asian country runs a 24 kilometer roundtrip on it the bus will receive 100 power unit (136 horsepower) electricity at is eighty fifth most power transmission efficiency rate whereas maintaining a seventeen $\mathrm{cm}$ air gap between the underbelly of the vehicle and conjointly the horizontal surface. At that power, only some sections of the road need embedded cables. Hybrid vehicles, that use an interior combustion engine combined with AN electrical engine to achieve higher fuel efficiency than AN everyday combustion engine, are already common. gas is in addition used as a transport fuel. Biofuels are a less common, and fewer promising, technology; Brazil met Revolutionary Organization 17 November of its transport fuel needs from bioethanol in 2007, but the OECD has warned that the success of biofuels in Brazil is because of specific native circumstances; internationally, biofuels are forecast to possess little or no impact on greenhouse emissions, at significantly higher price than energy efficiency measures.

In apply there is a scale of measurement of inexperienced transport counting on the sustainability of the selection. Inexperienced vehicles square measure extra fuel-efficient, but exclusively compared with traditional vehicles, which they still contribute to traffic congestion and road crashes.
Well-patronized transport networks supported ancient diesel buses use less fuel per person than personal vehicles, and square measure typically safer and use less road space than personal vehicles. inexperienced transport vehicles moreover as electrical trains, trams and electrical buses combine the advantages of inexperienced vehicles with those of property transport alternatives. Completely different transport alternatives with very low environmental impact square measure sport and various human-powered vehicles, and animal powered transport. the foremost common inexperienced transport various, with the littlest quantity environmental impact is walking.

Comparing completely different suggests that of transportation in terms of energy consumption appears to be terribly robust. that is the explanation why we have a tendency to tend to square measure making use of the ADEME environmental calculator. However, thus on produce things easier, we'll be victimization $\mathrm{kWh}$ and equivalent liter of gas per one hundred kilometers (1 l gas $=9.85 \mathrm{kWh}$ ). The figures given inside the table will regularly correspond to a primary energy.

Biologists, World Health Organization happen to be biochemists and biomechanics engineers any, teach USA that, relying of the air quantity that has been breathed, the consumed energy for walking, riding a bike or running are going to be evaluated albeit the muscle efficiency would amount to regarding two hundredth.

Table 1: Transportation per $100 \mathrm{~km}$

\begin{tabular}{|c|c|c|}
\hline & KM /H & Eq. Density \\
\hline Normal Walking & 7,5 & 0,8 \\
\hline Running on road & 8,5 & 0,9 \\
\hline Motor cycle & 2,5 & 0,25 \\
\hline
\end{tabular}

The energy consumption of an electrical automobile would quantity to ten until twenty $\mathrm{kWh}$ per one hundred kilometers. Whereas the electrical consumption of Associate in Nursing e-Golf is claimed to average twelve.7 kWh per one hundred kilometers at the electrical plug, in line with Volkswagen, the worth measured by the German automotive organization ADAC is very eighteen. $2 \mathrm{kWh}$ per one hundred kilometers.

Using the environmental calculator of the French ADEME, and presumptuous that the consumption of an electrical automobile at the plug is eighteen. $2 \mathrm{kWh}$ per one hundred kilometers (with Associate in Nursing potency of thirty-five.8\%, see Embodied Energy Embodied energy within the energy field) permits U.S. to fill within the following table:

Table 2: Per $100 \mathrm{Km}$ transportation with per passenger

\begin{tabular}{|c|c|c|}
\hline & KWH & Eq. L gasoline \\
\hline airplane & 51,7 & 5,1 \\
\hline Cars & 62,1 & 6,3 \\
\hline bikes & 51,0 & 5,3 \\
\hline Coaches & 20,5 & 2,2 \\
\hline Regional trains & 19,6 & 2,1 \\
\hline Trains & 15,1 & 1,6 \\
\hline High speed trains & 14,1 & 1,3 \\
\hline Trams & 5,5 & 0,8 \\
\hline Buses & 47,4 & 4,7 \\
\hline
\end{tabular}




\section{International Journal of Science and Research (IJSR) \\ ISSN (Online): 2319-7064}

Index Copernicus Value (2013): 6.14 | Impact Factor (2015): 6.391

\begin{tabular}{|l|c|c|}
\hline Electric cars & 50,3 & 5,4 \\
\hline
\end{tabular}

On average, the efficiency of combustion vehicles is dangerous, as explained by the shut sketch. It's accomplishable to undertake and do higher, with smaller cars. As a matter of reality, rolling resistance (above all thanks to the tires) decreases, to boot as energy. Since smaller cars sometimes drive extra slowly, the impacts of automotive mechanics are aiming to be lower too.

Rolling resistance on rails appears to be rather additional economical in terms of rolling resistance than tires. Moreover, a train created of many mortal cars shows on the common AN occasional mechanics resistance (in the table, the good efficiency of the really swift TGV may well be a symbol of it).

The Carbon Intensity of Travel: g CO2e/pkm

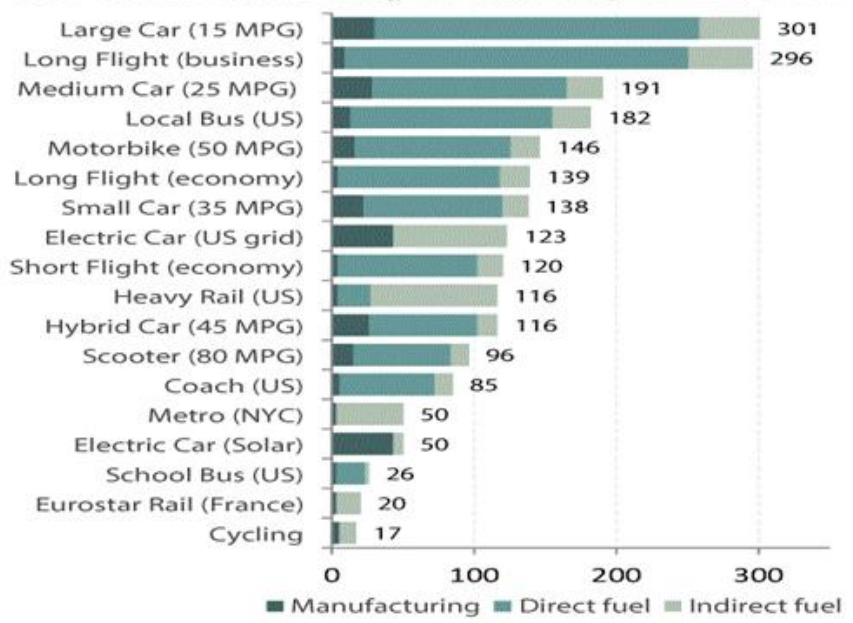

Figure 1: Elements of sustainable Transport

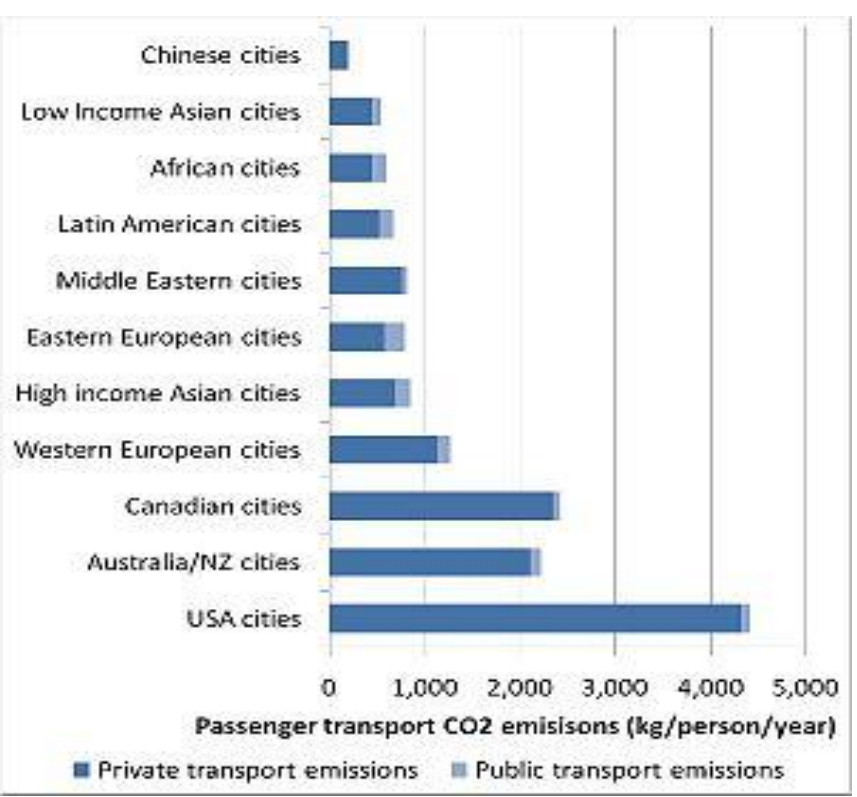

Figure 2: Passenger Transport transport policy. The methodology can incorporate a mixed methodology victimization totally different strategies. The analysis can compare totally different characteristics (e.g. distinction in wealth, ethnicity, or population density) against age so as to know however habits is engrained into individuals' travel movements. A comparison can therefore be achieved between the impact of habitual behavior across age and characteristics.

\section{References}

[1] Jeon, C M; Amekudzi (March 2005), "Addressing Sustainability in Transportation Systems: Definitions, Indicators, and Metrics"(PDF), JOURNAL OF INFRASTRUCTURE SYSTEMS: 31-50

[2] Helping to Build a Safe and Sustainable Transportation Infrastructure(PDF), U.S. Department of Transportation's Research and Innovative Technology Administration, May 2010

[3] Schafer, A. (1998) "The global demand for motorized mobility." Transportation Research A 32(6), 455-477.

[4] World Energy Council (2007). "Transport Technologies and Policy Scenarios". World Energy Council. Retrieved 2009-05-26.

[5] "About Transportation \& Climate Change: Transportation's Role in Climate Change: Overview DOT Transportation and Climate Change Clearinghouse". climate.dot.gov. Retrieved 2015-1115.

[6] Intergovernmental Panel on Climate Change (2007). "IPCC Fourth Assessment Report: Mitigation of Climate Change, chapter 5, Transport and its Infrastructure"(PDF). Intergovernmental Panel on Climate Change. Retrieved 2009-05-26.

[7] "National multipollutant emissions comparison by source sector in 2002". US Environmental Protection Agency. 2002. Retrieved 2009-03-18.

[8] World Health Organization, Europe. "Health effects of transport". Retrieved 2008-08-29. Archived April 30, 2010, at the Way back Machine.

[9] Social Exclusion Unit, Office of the Prime Minister (UK). "Making the Connections - final report on transport and social exclusion"(PDF). Retrieved 200302-01.

[10] Todd Littman (1998). "Measuring Transportation: Traffic, Mobility and Accessibility"(PDF). Victoria Transport Policy Institute. Retrieved 2009-03-18. External link in |publisher= (help)

[11]Todd Littman (2009). "Sustainable Transportation and TDM". Online TDM Encyclopedia. Victoria Transport Policy Institute. Retrieved 2009-04-07. External link in |publisher

\section{Conclusion}

This paper can contribute and process to encompassing the implementation of the sustainable transport. Thus, giving larger understanding of however property transports policies is compact as a results of age and characteristics which can permit this paper to tell future sustainable 